trimming off the surperfluous flannel along the dorsum of the foot, a narrow free margin of llannel which may be turned back on either side over the front edge of the plaster saturated foot-piece. After the splint is quite dry it can be easily opened, should it be thought desirable to have the leg available for future inspection, by running a pair of scissors down the seam along the front of the leg and the dorsum of the foot. The splint is afterwards held together by an ordinary roller bandage. In fact it is better in any case, even if the splint is not opened, to subsequently apply a roller bandage so as to hold the apparatus well together. When the splint is being prepared for a fracture just above the ankle-joint, a slight modification will ensure still greater strength where strength is most needed-that is, about the seat of fracture. In the splint just described, it has been noticed that just below the ankle there is only a single thick. ness of plaster-saturated flannel, as the lateral wings do not extend below this level. The desired increase in strength may be obtained as follows. The large oblong piece of flannel must in the first instance be cut an inch and a half longer than before. When the flannel has been sewn up, the superfluous free edges along the sole of the foot are trimmed off from the toes backwards, but only to within an inch and a half of the point of the heel. The remaining flannel being divided up the middle line behind as far as the end of the seam, two small side-pieces are formed which are turned upwaids, each over its respective malleolus, after the plaster-saturated side-pieces have been applied. Plaster solution is rubbed well into them, the large wings are turned back, and the splint is completed as before.

I may, perhaps, be here allowed to briefly touch upon a few points on which my preference for this particular form of plaster splint is based. In the first place, this splint is undoubtedly stronger and more durable than either of the other two plaster splints with which I am practically familiar - that is to say, Croft's and the Bavarian,-from both of which details in the making of this splint have been borrowed. And this advantage is obtained without the expenditure of any more labour in the making, and without any appreciable addition to the weight of the appliance. In a simple fracture-of one bone, for instance - this increased durability and strength are of little moment. But in a compound fracture, when the splint has to be opened more or less frequently for the purpose of dressing, and in fractures of both bones, when a splint which will atford the strongest possible support is necessary, it is a consideration of some little importance to have a splint which will stand the unavoidable amount of handling and strain, and will last out in an efficient state until is support is no longer necessary. Thus in such cases, and with a weaker splint than mine, it is usually necessary before the end of treat. ment either to apply a fresh apparatus or to strengthen the old one. A collateral advantage of durability in such a splint is that after it has served its purpose in the treatment of a fracture it is still of further use. In hospital practice it is extremely convenient to always have a stock of old splints on hand which, after they have been used for a fracture, may, if still of sufficient strength, be cut down and utilised in the treatment of sprained ankles and similar casualties. Another point to be noticed is that the continuous casing of flannel next the skin forms an efficient protection against the pressure exercised by the hard anterior edges of the side-pieces on the skin ; and thus, as I have already said, any tendency to the formation of pressure bullæ is absent. Then, again, with this method the amount of handling to which the fractured limb is subjected is reduced to a minimum ; the splint can be easily applied with the help of one assistant to keep up extension, and with comfort both to the patient and to the surgeon.

Other purposes to which splints made on the principle that $I$ have described may be put will now be briefly indicated. Excellent light splints for the knee or wrist in cases of arthritis may be made in a similar manner. In the case of the wrist-joint, a piece of flannel of an appropriate size is chosen. Its length should be such that it will reach from the distal extremity of the metacarpus to about three inches above the joint. This piece of flannel is folded lengthwise, and at the fold an oval aperture is made for the thumb. The flannel is then applied to the wrist, the thumb being inserted through the opening already made. The flannel is sewn together along the ulnar border of the wrist so as to encase the joint and leave two flaps, one to be turned back over the palm, the other over the dorsal aspect. Two small oblong slips of flannel are then cut out and saturated with plaster solution; one is applied to the back, the other to the front of the flannel casing. Over these pieces the two wings are turned back from the seam. Some plaster solution is then rubbed in, avoiding a narrow border along the seam and along the radial border of the wrist. A turn or two of the muslin bandage is then applied for five minntes or so. When, with an improved condition of the joint, the splint becomes loose, or, if dressings have to be applied, the seam is slit up and the splint tightened up with a roller bandage. For the knee the method of application is sufficiently obvious, and requires no further notice. So, too, convenient and close-fitting splints may be made for the elbow, whether for recent injury about the joint, for chronic disease, or for support after operation. By this method the splint may be shaped on the joint, the latter being kept at any angle which may be thought desirable. It will usually be more convenient to have the seam along the front rather than the back of the arm; the side-pieces will have to be cut so as to correspond with the angle at which the joint is to be kept.

In conclusion, I will add that so far as fractures of the leg are concerned I have purposely avoided all allusion to the class of fractures suitable for "immediate" treatment with this or any other form of splint. Some surgeons will limit it to simple fractures of one bone, others will extend it to compound fractures of the utmost severity. The conditions under which the patient has to be treated, his age, and in hospital practice the number of beds available for such cases, will all have their bearing on the matter. I am now merely suggesting that, given a fracture which the surgeon judges to be suitable for treatment by the "immediate" method, the particular form of splint which I have here described is one which presents certain advantages.

\section{NOTE ON THE \\ MORPHOLOGY OF THE CHOLERA COMMA BACILLUS.}

By G. F. DOWDESWELL, M.A., F.L.S., \&C.

WHATETER may be the relations of this microbe to the disease in which it occurs, its morphological characters are unquestionably most remarkable. It was some time after its notable discovery in cases of cholera by Dr. R. Koch that the significance of the so termed "commas" was generally recognised; that they were, in fact, but segments of a spirillum. The term "comma" in its English guise is not a happy one, but it has been overlooked, that, as I pointed out before, ${ }^{1}$ the term was not new, but had been used by Messrs. Ewart and Geddes ${ }^{2}$ in their account of the "Life History of Spirillum." In 1884, in the Proceedings, Royal Society, and in the following year in greater detail, in the Practitioner, Dr. E. Klein described and figured phases of this microbe where it formed round cells "spheroidal or discoid and vacuolated," which, as he wrote, "represent the initial stage of a mode of division different from the ordinary mode of transverse division." The appearances here described by Dr. Klein were received on the Continent with somewhat superficial criticism; in this country they were studiously overlooked or misunderstood by those who wrote upon the subject. ${ }^{3}$ It is obvious that these appearances represent developmental characters quite unprecedented amongst the schizophyta, and, admitting the generally received opinion that the cholera microbe belongs truly to this group, are altogether anomalons. I had an opportunity in 1884 and 1885 of observing the appearances obtained and described by Dr. Klein, both in fresh cultures and in permanent stained preparations which he gave me, but was unable myself at the time and for long subsequently to reproduce these forms in cultures from different sources. In January, 1889, however, I received from M. Ed. de Freudenreich, Director of the Bacteriological Department

1 Journal of the Royal Microscopical Society, 1885, p. $95^{\circ}$

2 Proceedings of the Royal Society, xxvii. (1878), p 484

3 As, quite recently, by the writer of a somewhat invidious notice in Nature (1890, p. 509), who asserts " that little if anything has been added to our knowledge of the mode of growth, its reaction to dyes, or its life history" of the comma bacillus, "since the account which Koch gave of it in 1834 ." 
of the Agricultural Institute, Rutti (Berne), cultures of the microbe in its ordinary or comma form which came from a source in the south of France; the first sub-cultures from this produced similar forms, but subsequently both the cultural characters and the forms of the microbes that developed showed some variations, and were similar to those mentioned below. In June, 1889, Dr. E. Klein gave me another culture of this microbe, the source of which was from India. In subcultures from it I obtained the appearances confirming those I had previously observed, and which I here briefly describe. When from these cultures in nutrient geiatine, after a considerable, but apparently variable and uncertain time and number of removes from the original source, bouillon peptone is inoculated and kept at the tempetature of $37^{\circ} \mathrm{C}$, , a grow th develops in from some hours up to two or three days or more, and the fluid becomes turbid. On examination under the microscope, small roundish cysts or coccoid bodies are ouserved, some of which are in active movement. There are also found small masses composed sometimes of minute granules or corpuscles, and sometimes of short fine filaments, or partly of both. Some of these masses have a distinct gyrating and progressive movement, sometimes tolerably rapid. Minute detached bacterioid orvibrioid particles may alio be seen, but very small and of rather indeterminate form. The coccoid cells and cysts are variable in size from two or three up to five or six mikrons or more in diameter. Soon there appear amcoboid forms, often in active movement; they are flagellated, and some at least are ciliated; they do not fuse together to form plasmodia, like the mycetozua, nor, as far as I have observed, do they usually conjugate; but I have observed clearly in one case at least (in, of course, a cell culture on the warm stage), that two of these corpuscles, both actively spinning about, the one pear-sbaped the other round, approached one another and became not fused or conjugated in the usual manner but united by a short filament, which was distinctly perceptible by a little management of the illumination. This was exactly analogous to what Dr. Dallinger has described and figured in the case of the infusorian monads: the two bodies remained dancing about together as long as I could keep them in sight. The size of these cells varies in length from the very minute up to nine or ten mikrons or more; they are frequently vacuolated, but I have observed no nucleus. A very common form is that of a pear or flask, and I have frequently observed a tendency to bilateral pseudopodial processes, which for some tine are persistent, but their forms, in fact, are protean.

After some time, often within ten hours of inoculation in tubes, the active round cells and the amœboid alike become quiescent, and vacuoles appear; the outline, too, becomes hard. This appears to be the encysted or resting stage; in some few, two or three short filaments or cilia are still apparent. Within twenty hours all these cysts bave collected into masses, are quiescent, and disintegration has commenced. In cell cultures they mostly collect near the margin towards the groove of the cell for the sake of aeration. They then break quickly up, when examined under the microscope from a tube of bouillon culture, but in the unciisturbed conditions of a closed culture cell more slowly, and they form what appear to be masses of minute granules, with some débris-filamentous or flocculent matter-amongst them, and some minute bacterioid or quasi-comma forms, but these, as far as I have been able to observe in cell cultures appear to be altogether effete, and not viable; it is the sporules only that are reproductive. These I have watehed over and over again under the microscope develop in to the forms described, and at the same time I have as of ten proved the absence of contaminations by plate cultures, after a modified method on the surface of solid nutrient media, in plugged tubes. The cell wall, too, breaks up into segments, which at first, for some hours, might be taken to represent the "commas" of the original cultures; but these segments, too, very shortly break up into small particles. These, together with those formed from the plasma of the cell, are found to be minute spherical corpuscles, two to three mikrons in diameter. They stain rather badly with any of the usual aniline dyes. The quiescent cysts may, I think, properly be termed "sporangia," and the corpuscles they form "sporules." This concludes the first cycle of transformations or alternation of generations in my observations. Sometimes, however, this succession of forms shows slight variations, speaking always of cultures of about the same distance in time from the original source. When inoculations in bouillon are made either from the same stock culture in gelatine, or the subculture in bouillon that has formed spornles as just deseribed, instead of the round mobile cells first appearing, active amobre are at once developed, which then form the round resting cells and sporules as above described ; or, again, under similar conditions, and this most frequently, no amoboid forms at all appear, but only round cells-first active and then quiescent. In cultures of a later date--in my case after some months ; i.e., removed by that length from the original source-I have, again, observed ancther generation or cycle of trunsformations; if from a subculture of this date tubes of bouillon peptone or culture cells at $37^{\circ} \mathrm{C}$. be inoculated, within generally about five honrs active development is observed, by the macroscopical appearance of the tubes or in the culture cells under the microscope. In this case there are formed filamentous masses of very varying size; the smaller of these are usually in active whirling and progressive motion. From the edges of these small masses sometimes a minute vibrio-like filament is detached and spins out of the field of view; but this is not frequent. I have, however, observed something of the kind previously, with cultures of the normal commas. The usual development of the large masses, which I have kept continuously on the warm stage under the microscope during the whole cycle of evolutions, is to steadily increase in size, forming masses of convoluted filaments, with, round the edges, a few of them in slight undulatiog motion hat without becoming detached, and, within twenty-four hours of inoculation, to break up into sporules, spleerical corpuscles precisely similar, as far as I can see, to those of the former cycle. With these their development ends. There also occur the small transient bacterioid or comma-like filaments before-mentioned. In this "generation," too, I have observed a variation, not unfrequent, but apparently arbitrary. In these cases, together with the masses of filaments, there appear bacillar cells, but of vastly greater thickness than the filamente. They are fully one mikron wide. Some are short and united in chains of a few cells, some are longer and more leptothrix-like, others are spirillar, and move with a sluggish rolling or rotatory movement; but they all appear to split up very shortly into small corpuscles, which I have not heen able to distinguish from those of the filamente. This completes the second cycle, or generation. Naturally, with these and other appearances observed, the first thought was that they were due to contaminations, but repeated and continuous observation on the warm stage and frequent separations showed that this was not so.

The appearances I have here descrilied I have observed both in cultures in tubes of bouillon in the inculator, ex anined in the natural state-that is, undried,--and in closed cells on the warm stage under the microscope, which is the only method, as it seems to me, to give reliable results on the morphology of the lower organisms, in the first instance at least. Without these I certainly should have missed some of the stages of these transformations, they occur so rapidly and are so evanescent. In watching the development of spores under the microscope, the first changes are frequently apparent within an hour and a half or even less, both in the formation of round cells, of those of amoboid form, or of leptothrix filaments. This latter process is very remark able. The spores at first commence to arrange themselves in linear order, they then elongate, forming the cells of the leptothrix filaments in sinuons or convoluted lines. In one instance I watched continuously a small mass of thirteen spores, which formed a slight twisted coil of the same minute cells, which elongated, formed short filaments, and again broke up.

In stained cover-glass preparations made ly different methods some further points are apparent; the cells of the filaments, in masses large or small, are seen to actually coalesce or be fused together, as if they were evolved out of a mass of primitive plasma. This cannot be distinguished in cell cultures or unstained preparations; at least I cannot do so. This appearance does not arise from heating the preparation, as when made liy other methods without heat or desiccation the same thing is seen. Again, in natural or unstained preparations it is somewhat difficult to distinguish the exact form of the sporulesformed from the plasma of the round cells or the filaments, but in a surcessful coverglass preparation they are seen, as I have described, to be minute round corpuscles. Here, again, there is a variation only seen in these stained preparations. In some few cases, where from the stage of masses of filaments they become separated and broken up, there are seen small groups of a 
few cells somewhat different from the general form of the filaments. They are short, bacillar, and appreciably thicker than the latter. Some few are slightly curved, not unlike the typical commas, but distinctly larger. They are not, however, as thick, nor do they appear as long as the large bacillar forms previously mentioned.

It was originally stated by Dr. Koch, and has been generally acknowledged, that the most distinctive character of the comma bacillus is its cultural habits : one of the earliest and most readily apparent indications of the transformations $I$ have described is a slight change in this habit; in cultures on gelatine with what I have termed the second and third generations or first and second cysles of transformations, irstead of developing at $15^{\circ} \mathrm{C}$. in the traditional manner within twenty-four hours, they develop slowly and with difficulty, only showing any growth after some or several days. In one case now before me, nearly four months old, the gelatine is not yet wholly liquefied. On the surface of the agar-agar at $37^{\circ} \mathrm{C}$. they develop sparingly; in the cold apparently not at all; and in bouillon at $15^{\circ} \mathrm{C}$, only after two or three days. In cultures of the first cycle of transformation in bouillon at $37^{\circ} \mathrm{C}$. I have frequently found distinct turbidity occur within an hour and a half of inoculation; this, with the methods I have employed-viz., ten to fifteen centimetres of bouillon inoculated with a small droplet, less than 001 centimetre-from a capillary tube, of an active growth, implies a development of upwards of a thousandfold within 120 minutes, which is more rapid than anything I have observed with any other microbes, ${ }^{4}$ and shows the occurrence of fission within every ten minutes. In the case of this rapid development, the forms, when examined on their first occurrence under the microscope, are always the small, round, active cells which follow the course of development already described. It is, however, only when inoculations are made from the sporules that this occurs. In the case here referred to, of the first cycle, the turbidity of the fluid is equable throughout-that is, no Hecks or particles are apparent. In the case of cultures of the second cycle, development in the tubes becomes apparent generally in about five hours, as $I$ have mentioned; but in this case there are apparent in the culture fluid minute flecks of particulate matter; under the microscope these are found to be the masses of fine filaments I have described above.

The phases of development here described are mainly the result of continuous observation upon cell cultures on the warm stage of the microscope ; the mode of development in tube cultures in the incubator agree with these as far as can be seen by discontinuous examination. The cells used, which I have employed for several years, I have previously described, but have lately found that they are identically the same as those known as "Ranvier's moist chamber." 5 They possess the great advantage of every part of their contents being accessible to examination with the highest powers, and also show very plainly the aerobic tendency or whe reverse of the organisms enclosed, according as they seek the periphery of the cell or not. In these cell cultures, too, the growth of any contamination is at once apparent. As it happens, however, in the locality in the country where these observations were made, the atmosphere is almost absolutely free from any form of the schizophyta, though teeming with various " moulds," the development of which, if it occurs, is very readily distinguishable. I have termed the corpuscles developed from the sporangia "sporules," to which, I think, they are clearly equivalent, and have frequently watched their germination in cell culture. They stand partial desiccation better than the original commas do, and in a culture fluid, even as partially dried seum or pellicle on the side of the tube, they retain their vinbility for about five months, but not for more than six. In stained preparations of the filaments some may be seen with deeply coloured corpuscles at intervals throughout their length, the plasma of the cell between them shrinking and obviously degenerating. Some have a corpuscle at one or both ends. Similar appearances have been described and seen by myself in the case of the typical "commas;" here, however, I think clearly the corpuscle is not "swollen"-i.e., it is not larger than the original width of the cell, but the cell itself both plasma and cell wall, if there is any such (of which I

4 This rapidity of development, though unprecedented amongst the schizopliyta, is not, however, comparible to what has been described in some fungi.

5 Described and figured in the recently published translation of Jorgensen's work, the Micro-organisms of Fermentation. am not sure), is shrunken, and rapidly disintegrating. Within a few hours nothing remains of it, but it must be remembered that the whole arrangement is very minute, distinctly under half a mikron. I think these corpuscles are properly termed spores, though not equivalent to the resting spores of bacilli.

What relations the sporangia, or round resting cells above described, have to the circles of Dr. Klein I am uncertain. I do not think they are altogether equivalenti e., probably they represent a developmental state of another cycle, or generation; but of this I am not sure. They certainly do not break up into the commas, or semicircles, described by Dr. Klein, and from the observation of them in the natural state they are evidently spherical, and not discoidal. The phase of development I have observed most recently, and which occurred pretty constantly, has been that of active round cells, with only a slight tendency to become amæboid, similar to the first cycle I have described. With these there occur minute, very active bodies, of a short, filamentous, irregular form, somewhat difficult to determine exactly. Watching these on the warm stage it appears to me that fertilisation occurs. The smaller bodies, which must be regarded as zoöspores, whirling rapidly about, approach the round cells, the oöspores, and remain in contact with them, the latter becoming quiescent. They then break up into the sporules before described, the whole course of development only occupying a few hours. As in other phases, some evanescent comma-like forms are developed, together with the sporules, It would be impossible to observe these changes excepting on the warm stage. What the significance of the fugitive large bacillar forms above-mentioned is it is difficult to say. As I recorded, ${ }^{6}$ there occur normally in the intestine of guinea-pigs large, curved bacillar bodies. These, I stated were much larger than the typical commas, and could not be confounded with them, though apparently fungoid." Then Mr. Watson Cheyne, in a paper published immediately afterwards, and which, indeed, must have been in the press on the appearance of mine, described and figured some "large worm.like bodies" in the same situation in guineapigs that had been experimented upon, though he mistook them for pathognomonic. Dr. Klein afterwards confirmed my observations on this subject, though without noticing them. These bodies are of very variable size and strange contorted form ; they are so unlike the normal commas that at the time (1884-85) I thought it impossible that there could be any genetic connexion between them. The forms I have above referred to remind me forcibly of them, and it is possible that they may be related. Mr. Cheyne stated that he knew of their relation by cultivation. Neither I, nor, I believe, others have succeeded in cultivating them from the intestine of the guinea-pig, and the difficulty of doing so may possibly proceed from the indisposition of the microbes in the cycles I have described to develop on the surface of gelatine or agar-agar.

What is now known as the "pleomorphism of the bacteria" was first demonstrated and established by the late Dr. Davaine many years ago, as is, or should be, known to every student of the subject. He showed that in the case of bacterium termo by inoculating it into the tissues of different plants bacillar, leptothrix, or corpuscular-cocoid form could be produced and changed at will, and that con sequently the classification of Ehrenberg, which divided the bacteria into genera characterised by their showing these forms, could not be relied on. Davaine in these experiments anticipated the exact methods of modern micro-biology established by Dr. Koch, as he did in other instances; for although the methods of obtaining pure cultures by plate separation were not then promulgated, yet he adopted the equivalent of one of the alternative methods of obtaining these advocated by Koch ${ }^{7}$ - viz., by inoculation (not, indeed, into the living animal, but in to the vegetable organism)and it is now a well-recognised maxim that without pure cultures no conclusions on this subject can be established.

This "pleomorphism" of the schizophyta is generally regarded as applying only to variations of form which have been recomnised as occurring normally in or characteristic of the different genera. It is quite obvious that in the various forms I have indicated we have a very different thing. It appears to me that we must regard these transformations as implying an alternation or alternations of generations. We have $A$, the so-termed commas and spirilla, whether or

6 Brit Med Journ., March 21st, 1885

7 Windinfections Krankheiten, English translation, pp. 68,69 C C 2 
not ending in sporules. This occurs for an indefinite number of generations; next, $B$, round ciliated active cells, and irregularly active amoeboid forms; then round resting cells (sporangia), ending with minute sporules. In the third generation we have from sporules active motile filaments, with the variation of large fugitive bacillar (? worm-like or spirillar) forms; these all alike terminate in sporules similar to those of the former generation. Again we have, as 1 have witnessed within the last few days, the second generation, $B$, succeeding or alternating with $C$, though it presents some variations. I have not succeeded by any methods I have yet tried in reproducing the normal commas, viable and reproductive per se. Comma forms do indeed occur amongst the different forms described, as I nave above mentioned, and in dried and stained cover-glass preparations perhaps no difference from the original typical commas might be apparent. It is almost entirely upon cell cultures and natural-i.e., living preparations from tube cultures that I have made my observations.

As is well known, Dr. Ferran has described some singular variations of form with "conidia" in cultures of the cholera microbe, and Dr. van Ermengem ${ }^{8}$ independently confirmed his statements, described and figured his results. I have followed the particular methods described by these authors, but without success. I do not, however, on that account, as has been commonly done, doubt the accuracy of their statements, or ascribe themtoo common a method of perfunctory criticism-to contaminations, with at least a skilled observer like Dr. van Ermengem. I have reason to believe that Dr. Klein and others have lately ohserved somewhat similar transformations to those I have described; how far their observations may agree with my own I do not know, but it would not surprise me if they had obtained forms widely different again. It is difficult to know to what class or even kingdom we are to assign these organisms. From their small size and the fugitive occurrence of the amœboid forms, I have not been able to pursue experiments to determine whether they belong to the animal or vegetable kingdom. It is possible that they may be allied to the imperfectly known sporozoa It is, however, clear either that this microbe is not one of the normal schizophyta, or if it be, then, as has been conjectured by some of the earlier writers on bacteria, that they do not represent an independent group, but are merely evolutional phases of some higher organisms, or perhaps only organs of other organisms.

I have shown above that the transformations are not only morphological, but physiological also, and it is not inconceivable that this may have some pathogenic significance. There is no occasion here to discuss the result of previous observations and statements as to the relations of this microbe to disease, that has been done by Dr. Klein in his last work, ${ }^{9}$ in a manner as logically clear, temperate, and candid, as conclusive to all unprejudiced persons; but to his exposition I will add one word from my own observations. In the experiments I made with the cultures I had obtained in 1884, briefly recorded in the British Medical Journal as above mentioned, I found that by injecting large quantities of the cultures subcutaneously into guineapigs what I at first regarded as choleraic symptoms were produced, but I quickly found, by examination of the rectal temperature, that it was septicæmia or sapræmia that was produced, and not cholera, the temperature rising at first rapidy and then falling gradually, instead of, as in cholera, falling steadily and progressively without any initial rise the curve of temperature was, in fact, precisely similar to that first described by the late Dr. Panum in his well. known observations on septic intoxication, and which 1 repeated many years ago, without, however, publishing them, as I had nothing to add to his conclusions. It is a remarkable fact that neither MM. Nicati and Rietsch, Dr. Koch, nor those who have repeated their experiments have given any notice whatever of the course of the temperature, a symptom which is at once conclusive of the distinction between chulera and sapræmia.

Our knowledge of bacteriology has suffered from so very few professed naturalists having worked at or given any attention to it. On the Continent they are few enough, in this country none at all. It is obviously desirable that systematic mycologists should give their attention to the transformations of this organism, with a view to determining its position and affinities. The observations in closed cells on

8 Sur le Microbe du Choléra, Bruxelles, 1885.

9 The Bacteria in Asiatic Cholera, London, 1889. the warn stage under the microscope are perfectly easy and satisfactory, nor do they necessitate the use of high powers. I must ald, both in justice to the maker and for the information of other observers, that the objective I have used almost entirely is a dry ${ }^{\prime \prime}$ by Messrs. Siwift of Tottenham-court-road. I have had the glass several years, and latterly have used it almost exclusively in observations upon microbes. Its price was extremely moderate, and its optical qualities in every respect excellent, putting to shame many objectives of much higher pretention and cost; being dry and not immersion is a great advantage, while it is so good and light, that it stands very deep eye-pieces, riving, if necessary, an amplification of fully 1000 diameters. Excepting for micrometry higher powers are almost superfluous. I must, however, add that I by no means intend to disparage the lenses of other makers. Douhtless there are many that are excellent, as, e.g., two, a ?" and $\frac{1}{3}$ ", both dry, by Messrs. Beck and Co., of Cornhill, of exceedingly moderate price, and of which the optical qualities are excellent, whilst the adnirable productions of Dr. Zeiss of Jena are too well known to need commendation. I record this more particularly for the information of those who may not be familiar with the use of the high powers of costly price so much vaunted now by some, and whom the fancied necessity for the use of them might deter from examining this subject. The conditions which determine these transformations are very obscure. They appear only to occur in cultures that are removed from the original source by a considerable length of time. The temperature influences them in the rapidity with which they are completed; the composition of the culture medium affects them very greatly. Very remarkably, I have found latterly that the forms here described will not develop at all at any temperature in bouillon (with peptone and $\mathrm{NaCl}$ as usual) unless of a high degree of concentration of fully sp. gr. 1008 (the plain bouillon)-that is, more in accordance with the formula of Dr. Koch than that of Dr. Miguel, which for the majority of microbes I have found preferable.

I have here only described a portion of the appearances I have observed. The amœboid forms, various and grotesque as they are, are cenerally difficult to preserve; but I have photographs of some of them, admirably taken by $\mathrm{Mr}$. Andrew Pringle, which hereafter I may publish with further particulars. Anomalous as such transformations are amongst the schizophyta, they are nothing either in variety or the rapidity with which they are completed to what has been observed and perfectly well established anıongst nicrofungi. I feel confident that the phases I have described will be confirmed and perhaps widely extended by others, if they well observe the development of this organism on the warm stage in the manner I have done.

P.S. - Further examination of the characters of the sporozoa has confirmed the opinion I have above expressed, that the microbe here described probably belongs to that class. In Balbiani's "Leçons sur les Protozoaires" (Paris, 1884) I find forms described and figured which strongly resemble some phases of the cholera microbe which I have cultivated and of which I have drawings, especially is this the case with what Balbiani figures as the "Macrospores of the Monocystis of the Eartliworm." 10 These are in form almost exactly like a phase which I have found very frequent and characteristic.

On May 22nd last Dr. E. Klein described to the Royal Society, and showed photographs of, a developmental form of the bacillus tuberculosis, which was apparently truly branched, and therefore clearly could not belong to the schizophyta, but appeared to be a mycelial fungus. Owing, however, to the restrictions of the Society I was unable to obtain a print of his paper, and consequently can offer no further opinion upon it; but the circumstance seems clearly to support the view that some at least of the so termed schizophyta are but developmental forms or transitory phases of higher organisms. Other circumstances, too, support this view with regard to some of the a.sporous species. During the summer months bacterium termo is proverbially ubiquitous, with other species, any resting form of it is not known; in an exhausted culture it dies out in a few weeks, and somewhat more quickly if desiccated; during the winter it disappears entirely, as I have found in two successive years, and cannot then be reproduced by any cultural methods, but it reappears everywhere again in the summer. The only intelligible explanation of this is that 
the bacterium is only a developmental and transitory phase of some other organism, though the latter has not yet appeared in artificial cultures. It is not, however, necessary to suppose that this is the case with all forms or species of the schizophyta; on the contrary, the sporiferous species in all probability form an independent group, and we may know the whole cycle of their developmental history. would, however, protest most strongly against a tendency that has been shown by some writers to include in the same group sporiferous and a-sporous species, the bacteria and the bacilli, on account of the nost superficial resemblance in form, thereby violating the accepted principle of the modern classification of the thallophytes-viz., according to the characters of their reproduction, which is recognised by the highest authorities on this subject both on the Continent and in this country.

Finally, I would emphasise what I have said above, that the forms of this microbe, some of which I have very briefly described, or those of any similar organism, can only be properly observed in suitable culture chambers. In the words of Maupas,11 "Il faut d'abord et avant tout se pourvoir de chambres humides convénablement disposées."

\section{CASE OF CASAREAN SECTION FOR OSTEO- MALACIC PELVIS.}

BY WILLIAM McGOWAN, M.D., MEDICAL OFFICER, MIGHERA DISPEYSARY, CO. DERRT.

ON Dec. 4th, 1889, I was called upon to attend in labour I. McC_- the wife of a farm labourer. I saw her at her residence, about two miles distant, at $7.30 \mathrm{~A}$. $\mathrm{x}$. The patient, aged thirty-seven, a small, delicate, emaciated woman, was the mother of five children, and all her previous labours had heen natural and easy. I myself attended her at her last confinement, on Aug. 17th, 1881, when the pelvis was quite natural and roomy, and she had an easy labour, not even the forceps being required. After this I lost sight of her, but there was the history of her having, immediately following this confinement, to keep her bed for over six months from what was called "rheumatic pains." For some six months or so more she was only able to be carried to a chair at the fire. After this she began to go about a little on crutches, and gradually gained strength, but remained permanently "bent in the back," "sunk," and "stooped." During the latter months of gestation she said her health had been very bad, and scarcely anything was retained on the stomach, so that she was very weak. When I saw her she had been about fortytwo hours in labour, and yet, as she said, "it was doing no good ; the lump had not gone down as it used to do." Examination revealed an extreme degree of pelvic contraction and deformity. The tubera ischia were less than threequarters of an inch apart, almost obliterating the pubic arch so closely approximated were they that the index finger could only with some difficulty pass between them. The sacrum and coccyx projected forwards, leaving only a narrow chink between them and the approximated ischia. For want of space, caused by this narrowing of the outlet, it was impossible to make out the presentation.

As delivery by the natural passage seemed impossible, I sent for my friend, Dr. Thompson of Bellaghy, who arrived sbortly after 10 o'clock. On examining her, he agreed with me that the only chance of delivery must be by the Crsarean section. The nature and dangers of the operation were explained, and, the sanction of the patient and her husband having been unhesitatingly obtained, we determined to lose no time in carrying out the operation, as the powers of nature were already greatly exhausted by the prolonged labour. Giving directions to have the house thoroughly heated and other preparations made, I returned home for the necessary instruments \&c., and proceeded again to the house at 12 o'clock, accompanied by Dr. Thompson and Dr. Hueston, of Maghera, who kindly afforded me their valuable advice and assistance. The patient was lying in the kitchen of a farm labourer's cottage, so that the surroundings were not favourable for a serious operation. However, there was no alternative. The rectum was well cleared out by an enema, a catheter passed, and the patient

11 Arch. de Zool. Expt., 1888. placed on a suitable table and put under the influence of chloroform. With the strictestantiseptic precautions possible under the circumstances the usual incision was made, and without any difficulty I speedily removed a living child, healthy and fairly well developed. In making the incision in the uterine wall I came on the placenta attached to the anterior surface. This I cut through, and the child and placenta were removed without any trouble from hæmorrhage. Owing probably to exhaustion caused by the prolonged labour the uterus did not contract well. After ascertaining that the passage to the vagina was patent, the uterus was sutured by chromicised catgut passed deeply into the tissue. The peritoneal cavity was sponged out, and the wound in the abdominal wall secured by six silk sutures passed deeply so as to include the whole thickness of the wall and peritoneum, and superficial ones through theskin between these. The wound was dusted with iodoform, covered with wood wool, and secured by four broad strips of adhesive plaster and a flannel binder over all. The external genitals were covered with carbolised tow and cotton wool. During the suturing of the external wound vomiting set in from the chloroform, but it soon ceased, and the patient was put to bed with a pulse, though weak, as good as before the operation. A hot-water jar was put to her feet, her head covered with flannel, and a hypodermic injection of morphia given. In the evening I found her in a satisfactory condition, but retching and vomiting at intervals. Ordered nothing to be given by the mouth except small quantities of brandy and iced soda-water. Passed the catheter.

Dec. 5th : Comfortable, but retching a little. Passed catheter. In the evening she complained of rather severe pain in the right side of the abdomen, with accelerated breathing. Temperature $99 \cdot 4^{\circ}$; pulse 136 . Gave a quarter of a grain of morphia hypodermically; passed catheter and syringed ont the vagina with carbolic acid lotion. One grain of opium to be given every four hours until pain ceased. -6 th : Found her much better, baving slept after the morphia; pain almost gone. Expressed herself as feeling comfortable; had passed urine voluntarily. For the next two days her condition was fairly satisfactory; scarcely any pain. Temperature never higher than $99 .^{\circ}$, but pulse continued to increase in rapidity and weakness. During the entire treatment, nourish ment was given by means of enemata, consisting of beef-tea, brandy, egg, Benger's food, \&c., which were well retained. The vagina was syringed out regularly, and the discharge remained heal thy.

On the evening of the 8 th $I$ found her worse delirium and restlessness had set in and continued until her death, which occurred at 6 P.M. on Dec. 9th, the sixth day after operation. On removing the dressings after death, I found the wound in the abdomen healed, and not a drop of pus was observed. There was gaping between two of the sutures, but this was evidently caused by her restlessness before death, when she could only with difficulty be restrained from tearing off the dressings. I got permission only to reopen the abdominal wound, so that the examination was very limited, and it was also under the circumstances hurried. I found the stomach and intestines much distended with flatus. There was marked peritonitis with adhesions, which probably set in on the day after the opera tion. The uterus was forced down by the distended intestines, was well contracted, and there appeared complete union of the uterine wound. There was no blood or effusion in the abdominal cavity.

Remarks.-As she got over the period of collapse and escaped the second great danger-namely, septicremia-hopes were entertained of recovery. The cause of death was peritonitis, and I may call attention to the obscurity or "latency" of the symptoms. Except for two or three hours she scarcely suffered any pain, and her temperature was never above $994^{\circ}$. The most marked feature was the accelerated pulse, gradually increasing in rapidity and weakness, which might have been an indication of ex. haustion or prolonged collapse, independent of peritonitis, taking into consideration her enfeebled condition at the time of operation. Notwithstanding the unfavourable result to the mother, the case seems to me of interest, not on account of anything novel in the performance of the operation or unfortunately in the result, but from the nature and rarity of the deformity necessitating the operation. There can be no doubt of this being a case of mollities ossium occurring in adult life. The pelvis was characteristic of this deformity and contraction. The nature of the outlet has been already described, and from the slight necropsy 